\title{
Prevalence of atopy, asthma symptoms and diagnosis, and the management of asthma: comparison of an affluent and a non-affluent country
}

\author{
Adeola Olusola Faniran, Jennifer K Peat, Ann J Woolcock
}

\begin{abstract}
Background-The prevalence of childhood asthma and of atopy varies widely between countries. However, few studies have compared the pattern of diagnosis and management of asthma, or the role of atopy in predisposing to asthma between a less affluent country and a more affluent country. The aim of this study was to compare the prevalence of symptoms, diagnosis, and management of asthma, and the prevalence of atopy as measured by skin prick tests in Nigeria and Australia using a standardised methodology.

Methods-Respiratory history was collected using a validated questionnaire administered to parents, and atopy was measured with skin prick tests in 654 Australian and 566 Nigerian children aged 8-11 years (70\% consent rate in Australia, $60 \%$ in Nigeria).

Results-Wheeze and persistent cough were less prevalent in Nigeria $(10.2 \%$ and $5.1 \%$, respectively) than in Australia $(21.9 \%$ and $9.6 \%$, respectively), caused less morbidity, and were less likely to be labelled or treated as asthma than in Australia. There was no significant difference in the overall prevalence of atopy between the two countries (Australia 32.5\%, Nigeria $28.2 \%$ ). Atopy was a strong risk for wheeze in both countries (odds ratio (OR) $3.4(95 \%$ CI 2.3 to 5.1) in Australia, 1.8 (95\% CI 1.0 to 3.3 ) in Nigeria), especially atopy to house dust mites (OR 3.1 (95\% CI 2.1 to 4.7 ) in Australia, 2.4 (95\% CI 1.3 to 4.3) in Nigeria).

Conclusion-Although there was a similar prevalence of atopy in both countries, Australian children had a higher prevalence of asthma symptoms. Further studies are needed to determine why atopic children in Australia are more at risk of developing asthma. Such studies will have important implications for the prevention of asthma.

(Thorax 1999;54:606-610)
\end{abstract}

Institute of

Respiratory Medicine, University of Sydney Department of Medicine, PO Box M77, Camperdown, NSW 2050, Australia A O Faniran

A J Woolcock

Clinical Epidemiology Unit, University of Sydney Department of Pediatrics and Child Health, New Children's Hospital, Westmead, NSW 2145, Australia J K Peat

Correspondence to: Dr A O Faniran.

Received 8 June 1998 Returned to author 20 August 1998 Revised manuscript received 15 March 1999 Accepted for publication 17 March 1999

Keywords: prevalence; asthma; symptoms; atopy; international; children

There have been increasing numbers of studies comparing the prevalence of asthma worldwide. In a recent study ${ }^{1}$ the reported prevalence of asthma and atopic diseases varied widely between and within countries, with affluent English speaking countries having the highest levels. Also, in this study the researchers reported a high prevalence of rhinoconjunctivitis and eczema symptoms in some non-affluent countries such as Nigeria where the prevalence of asthma symptoms was low. ${ }^{1}$ These differences in prevalence may result from different allergen exposure, different environmental factors, or different racial susceptibility. On the other hand, diagnosis and treatment patterns are often different between racial groups for comparable severity of the disease, and this may also account for some of the differences found. In non-affluent countries cough is more likely to be diagnosed as an infection such as pneumonia or tuberculosis than as asthma because these infections are common. ${ }^{2}$ However, in affluent countries cough is likely to attract a diagnosis of asthma. ${ }^{3}$

The aim of this study was to confirm this pattern of distribution of asthma symptoms and atopic symptoms and to collect objective data about the prevalence of atopy in Nigeria, a non-affluent country, and in Australia, an affluent country. We also measured and compared the prevalence and characteristics of asthma symptoms and the diagnosis and management of asthma in these two regions. Standardised methods were used in both regions to compare estimates.

\section{Methods}

To detect a difference of $10 \%$ in the prevalence of wheeze between Australia and Nigeria a minimum of 286 children were needed in each group $(90 \%$ power, $\mathrm{p}=0.05)$. However, a larger sample of 600 subjects was chosen to measure the prevalence with more precision.

In Nigeria a local government area (Ojo), which is the most populated local government area in Lagos, was chosen. This area was representative of Lagos in that it included families with a wide range of socioeconomic status. A list of all public and private primary schools in this area was compiled and separate sampling frames for school type were used. Three schools were selected in each frame using a table of random numbers. In the initial set up of the study the plan was to recruit 170 children from each class; however, some schools did not have sufficient children and, as a result, self-administered questionnaires with an explanatory letter to parents were distributed to a total of 930 children in classes 3-6 at each school (age range 8-11 years). 
Table 1 Prevalence of symptoms and morbidity associated with asthma in 8-11 year old Australian and Nigerian children

\begin{tabular}{llll}
\hline & Australia $(n=654)$ & Nigeria $(n=566)$ & p value \\
\hline Wheeze ever & $35.0(31.4$ to 38.7$)$ & $15.0(12.1$ to 17.9$)$ & $<0.001$ \\
Recent wheeze & $21.9(18.7$ to 25.1$)$ & $10.2(7.7$ to 12.7$)$ & $<0.001$ \\
Wheeze $\geqslant 4$ times in the last 12 months & $18.7(15.7$ to 21.7$)$ & $5.3(3.5$ to 7.2$)$ & $<0.001$ \\
Cough ever & $25.8(22.5$ to 29.2$)$ & $10.8(8.2$ to 13.4$)$ & $<0.001$ \\
Persistent cough & $9.6(7.3$ to 11.9$)$ & $5.1(3.3$ to 6.9$)$ & $<0.001$ \\
Early respiratory illness & $12.8(9.2$ to 15.4$)$ & $7.2(5.1$ to 9.3$)$ & $<0.01$ \\
Hayfever in the last 12 months & $28.4(24.9$ to 31.9$)$ & $25.6(19.3$ to 26.5$)$ & NS \\
Morbidity associated with asthma in the last 12 months & & \\
$\quad$ Limited activity $\geqslant$ some days & $14.2(11.1$ to 17.3$)$ & $5.5(3.7$ to 7.3$)$ & $<0.001$ \\
Sleep disturbed $\geqslant$ some nights & $16.4(13.4$ to 19.4$)$ & $7.8(5.4$ to 10.2$)$ & $<0.001$ \\
$\quad$ Missed school $\geqslant$ some days & $12.5(10.0$ to 15.0$)$ & $5.1(3.3$ to 6.9$)$ & $<0.001$ \\
\hline
\end{tabular}

Figures are percentages with $95 \%$ confidence interval in parentheses.

In Australia a list of public schools within a $10 \mathrm{~km}$ radius of Royal Prince Alfred hospital, Sydney, Australia was compiled. All children in class years 3-6 (age range 8-11 years) were selected. Schools with less than 80 children were excluded for logistic reasons. Questionnaires were distributed to a total of 930 children. Children were invited to participate in this study through a letter to parents and/or guardians.

Prior to the day of skin prick testing, a team member visited classes to remind children to return questionnaires and to answer any questions. A reminder letter was sent home to parents with an attached consent form, and second questionnaires were issued at testing. As far as possible, all non-responders were surveyed to assess possible sampling bias. Each non-responder was given an option to complete the questionnaire without having a skin prick test and, in cases where they refused, they were asked whether any medication for asthma had been used in the last 12 months. Children who were studied were also asked exactly the same question for comparison.

Atopy was measured by skin prick tests using a panel of eight common allergens (HollisterSteir, Miles Inc, Elkhart, Indiana, USA). The allergens tested were house dust mites (Dermatophagoides pteronyssinus and Dermatophagoides farinae), house dust, rye grass, mould (Alternaria tenius and Cladosporum), cat dander, and cockroach. These allergens, together with positive (histamine) and negative (glycerol) controls, were applied into a stencil stamped on the forearm with ink and pricked with a lancet (long point microlance, BectonDickson, Rutherford, New Jersey, USA). The studies were approved by the human ethics committee of the University of Sydney and by the research committees of the Lagos State

Table 2 Prevalence of asthma diagnosis and asthma medication use in 8-11 year old Australian and Nigerian children

\begin{tabular}{|c|c|c|c|}
\hline & Australia $(n=654)$ & Nigeria $(n=566)$ & $p$ value \\
\hline Doctor diagnosis of asthma ever & $28.0(24.6$ to 31.4$)$ & $6.0(4.0$ to 8.0$)$ & $<0.01$ \\
\hline Diagnosis of asthma in persistent cough group & $\begin{array}{l}39.0(22.3 \text { to } 55.7) \\
(\mathrm{n}=63)\end{array}$ & $\begin{array}{l}0 \\
(n=29)\end{array}$ & $<0.001$ \\
\hline Diagnosis of asthma in recent wheeze group & $\begin{array}{l}77(70.0 \text { to } 84.0) \\
(\mathrm{n}=143)\end{array}$ & $\begin{array}{l}42.7(29.6 \text { to } 55.8) \\
(\mathrm{n}=58)\end{array}$ & $<0.001$ \\
\hline Asthma medicine ever & $31.3(27.8$ to 34.9$)$ & $6.5(4.5$ to 8.5$)$ & $<0.001$ \\
\hline Ventolin in the last 12 months & $18.5(15.5$ to 21.5$)$ & $5.8(3.9$ to 7.7$)$ & $<0.001$ \\
\hline Intal in the last 12 months & $4.7(3.1$ to 6.3$)$ & $0.4(-0.1$ to 0.9$)$ & $<0.001$ \\
\hline Becotide in the last 12 months & $10.4(8.1$ to 12.7$)$ & $0.2(-0.2$ to 0.6$)$ & $<0.001$ \\
\hline
\end{tabular}

Figures are percentages with $95 \%$ confidence interval in parentheses.
School Education Board and the New South Wales Department of School Education.

QUESTIONNAIRE

A self-administered questionnaire to parents was used to measure respiratory symptom history, frequency of symptoms, medication use, and the morbidity caused by asthma and persistent cough (cough lasting more than three weeks). The questionnaire was a modified version of one developed by the Institute of Respiratory Medicine, University of Sydney. ${ }^{4}$ The questions included recent symptoms relating to the 12 months prior to the study and the presence of respiratory symptoms since birth. Symptom frequency was used as a measure of the severity of asthma and persistent cough. Each child had his/her questionnaire checked for completeness and parental consent signature. When incomplete, parents were telephoned or the questionnaire returned with a reply-paid envelope and a request to complete. When necessary, non-returners were contacted by telephone to retrieve the questionnaire.

\section{DEFINITIONS}

Recent wheeze was defined as the presence of wheeze or exercise wheeze in the last 12 months, and persistent cough was defined as the presence of a cough lasting for more than three weeks without a cold or flu in the last 12 months. Early respiratory infection was defined as a serious respiratory illness such as bronchitis, bronchiolitis, or pneumonia treated by a doctor or at a hospital before the age of two. Atopy was defined as a weal size of $3 \mathrm{~mm}$ or more to any of the allergens.

STATISTICS

Data were stored in a clinical reporting system (CRS) database on an IBM-PC and analysed using the statistical package program SAS (SAS Institute Inc, Cary, North Carolina, USA). Prevalence rates were compared between the two populations using a $\chi^{2}$ test.

\section{Results}

The participation rate was $60.8 \%$ in Nigeria ( $\mathrm{n}$ $=566)$ and $70.3 \%$ in Australia $(n=654)$. The prevalence of symptoms and morbidity associated with asthma in the two groups is shown in table 1. Nigerian children had a significantly lower prevalence of symptoms (except hayfever) than Australian children $(\mathrm{p}<0.001)$. In addition, significantly more Australian children had limited activity on some days, had their sleep disturbed on some nights, and missed school some days due to asthma $(\mathrm{p}<0.001)$.

Table 2 shows that significantly fewer Nigerian children had ever been diagnosed as having asthma or had used asthma medication compared with Australian children. Also, in Nigeria, significantly fewer children with recent wheeze and no child with persistent cough had ever been diagnosed as having asthma by a medical doctor $(\mathrm{p}<0.001)$.

Table 3 shows that significantly fewer Nigerian children regularly visited a doctor for asthma (at least every six months) or had 
Table 3 Use of medical services for asthma in 8-11 year old Australian and Nigerian children

\begin{tabular}{|c|c|c|c|}
\hline & $\begin{array}{l}\text { Australia } \\
(n=654)\end{array}$ & $\begin{array}{l}\text { Nigeria } \\
(n=566)\end{array}$ & $p$ value \\
\hline Doctor visit $\geqslant 6$ monthly & 8.7 (6.9 to 10.5$)$ & $3.1(2.0$ to 4.2$)$ & $<0.001$ \\
\hline Casualty visit for asthma in the last 12 months & $6.8(4.5$ to 9.1$)$ & $2.1(1.2$ to 3.0$)$ & $<0.001$ \\
\hline Hospital admission in the last 12 months & $1.8(0.8$ to 2.8$)$ & $0.6(-0.2$ to 1.4$)$ & NS \\
\hline In children with a doctor diagnosis of asthma & $\mathrm{n}=183$ & $\mathrm{n}=34$ & \\
\hline Doctor visit $\geqslant 6$ monthly & $67.5(60.2$ to 74.8$)$ & $41.7(23.3$ to 60.1$)$ & $<0.05$ \\
\hline $\begin{array}{l}\text { Casualty visit for asthma in the last } 12 \\
\text { months }\end{array}$ & $20.0(11.4$ to 28.6$)$ & $21.3(9.6$ to 33.0$)$ & NS \\
\hline Hospital admission in the last 12 months & $5.1(0.4$ to 9.8$)$ & $5.0(-1.3$ to 11.3$)$ & NS \\
\hline
\end{tabular}

Figures are percentages with $95 \%$ confidence interval in parentheses.

Table 4 Prevalence of atopy in Australian and Nigerian children

\begin{tabular}{llll}
\hline & Australia $(n=570)$ & Nigeria $(n=521)$ & p value \\
\hline Atopy & $32.5(28.7$ to 36.4$)$ & $28.2(24.3$ to 32.1$)$ & NS \\
House dust mites & $28.2(24.5$ to 31.9$)$ & $20.7(17.2$ to 24.2$)$ & $<0.01$ \\
$\quad$ D farinae & $23.5(20.0$ to 27.0$)$ & $15.4(12.3$ to 18.5$)$ & $<0.001$ \\
$\quad$ pteronyssinus & $23.5(20.0$ to 27.0$)$ & $17.5(14.4$ to 20.6$)$ & $<0.05$ \\
Rye grass & $9.1(6.7$ to 11.5$)$ & $2.5(1.2$ to 3.8$)$ & $<0.001$ \\
House dust & $4.6(2.9$ to 6.3$)$ & $5.4(3.5$ to 7.3$)$ & NS \\
Cladosporium & $1.4(0.4$ to 2.4$)$ & $2.7(1.4$ to 4.0$)$ & NS \\
Cockroach & $6.3(4.3$ to 8.3$)$ & $9.0(6.6$ to 11.4$)$ & NS \\
Alternaria & $2.6(1.3$ to 3.9$)$ & $2.7(1.4$ to 4.0$)$ & NS \\
Cat & $5.6(3.7$ to 7.6$)$ & $3.6(2.1$ to 5.1$)$ & NS \\
\hline
\end{tabular}

Figures are percentages with $95 \%$ confidence interval in parentheses.

visited a hospital casualty department in the last 12 months $(\mathrm{p}<0.001)$. Only a small proportion of Australian and Nigerian children had been admitted to hospital for breathing problems in the last 12 months. Significantly fewer Nigerian children who had been diagnosed as asthmatic had visited a doctor regularly for asthma $(\mathrm{p}<0.05)$. Again, only small proportions of Australian and Nigerian children who had been diagnosed as asthmatic had visited a hospital casualty department or been admitted to a hospital for breathing problems in the last 12 months.

Table 4 shows that there was no significant difference in the proportion of Australian and Nigerian children who were atopic. However, significantly more Australian children were sensitised to house dust mites $(\mathrm{p}<0.01)$, especially $D$ farinae $(\mathrm{p}<0.001)$, and to rye grass $(\mathrm{p}<0.001)$. Both Australian and Nigerian children were significantly more likely to have recent wheeze if they were atopic to house dust mites (odds ratio (OR) 3.1 (95\% CI 2.1 to 4.7 ) and 2.4 (95\% CI 1.3 to 4.3 ), respectively) or to any of the allergens (OR 3.4 (95\% CI 2.3 to 5.1 ) and 1.8 (1.0 to 3.3), respectively). Although the magnitude of the effect was higher in Australia, this difference was not significant.

\section{Discussion}

This study shows that Nigerian children have significantly fewer respiratory symptoms and are less likely to be diagnosed with asthma or to use asthma medications than Australian children. The prevalence of asthma symptoms in Nigerian and Australian children was similar to that reported in previous studies using similar methods. ${ }^{15}$ Although there was no significant difference in the overall prevalence of atopy between the two countries, significantly more Australian children were sensitised to house dust mites and to rye grass.
Some of the differences in prevalence between the two countries may be explained by an increased level of awareness in Australia as a result of several public health awareness campaigns and the emphasis placed on asthma symptoms. However, differences in diagnostic criteria between the two countries may be important. In Nigeria other more life threatening and endemic diseases such as tuberculosis, measles, and malaria are prevalent and may remove the focus from diseases such as asthma. $^{2}$

We found a significant difference in the management of asthma between the two countries. Among children with wheeze, which is the most likely symptom to be diagnosed as asthma, a significantly lower proportion of children had been diagnosed as asthmatic in Nigeria than in Australia $(43 \%$ and $77 \%$, respectively) while no child in Nigeria with persistent cough had been diagnosed as asthmatic compared with $39 \%$ in Australia. The interpretation of these figures is difficult because the questionnaire was not able to distinguish between cough associated with asthma, chronic cough, or other conditions of which cough is a symptom.

There was also a low proportion of children (in both those diagnosed as asthmatic and in the total sample) who used a preventive medication or visited a doctor routinely in Nigeria compared with Australia. However, a similar proportion of children with a diagnosis of asthma in both countries visited a hospital casualty or were admitted to a hospital for breathing problems. This suggests that, in Nigeria, asthma is more likely to be managed in the acute form with very few children returning for follow up. Because fewer Nigerian children had missed school, had limited activity, or had disturbed sleep because of asthma, and hardly any Nigerian child was taking inhaled corticosteroids, it is likely that asthma is generally less severe in Nigerian children.

In a study conducted in Fiji, national hospital admission data for respiratory illness in 5-14 year old Melanesian and Indian children showed that, between 1985 and 1989, admissions for asthma were three times higher in Indian than in Melanesian children. ${ }^{7}$ However, during the same period, Melanesian children had more than threefold higher admission rates for pneumonia and other respiratory infections including influenza, tuberculosis, and bronchiectasis. This suggests a difference in the disease patterns of children from different races, even when they live in the same country. On the other hand, doctors may use different diagnostic patterns for children of different races which may be based on their clinical experience. We did not expect to find that Nigerian children had a lower prevalence of persistent cough and early respiratory infections than Australian children. The prevalence of acute respiratory infection is similar between developed and developing countries with children having about 5-8 episodes a year, each episode lasting for a mean of 7-9 days. ${ }^{2}$ However, the prevalence of severe lower respiratory infections such as pneumo- 
nia is reported to be higher in developing countries, ${ }^{2}$ suggesting that the prevalence of early respiratory infections would be higher in Nigerian children.

Positive skin prick test reactions to allergens were determined by criteria which have been validated against symptoms and airway hyperresponsiveness. ${ }^{48}$ The construct validity of skin prick tests against asthmatic symptoms has also been shown to be similar to that of total serum IgE levels. ${ }^{9}{ }^{10}$ The prevalence of atopy in Nigerian children using the eight allergens selected in this study is likely to be representative of atopy in Nigeria because they have been reported to be common in Nigeria. ${ }^{6}{ }^{11} 12$

Although the prevalence of atopy was similar between the two countries, Australian children had a higher prevalence of wheeze and asthma. This finding is similar to that reported in a study comparing the prevalence of asthma and atopy between rural and urban Ethiopia. ${ }^{13}$ In this study none of the atopic individuals in the rural area reported wheeze or asthma and the authors suggested that atopy may be associated with a decrease in asthma symptoms.

It is possible that being atopic does not predict the probability of having asthma or, more likely, that atopy has to be combined with other environmental factors present in affluent countries like Australia in order to predispose children to having asthma. It is possible that cultural or awareness differences could have contributed to the large difference in symptom reporting between Australia and Nigeria. However, it could also be that a protective mechanism in the airways of sensitised children in Australia may have been altered by environmental factors such as different dietary habits ${ }^{14-16}$ which may have led to immunological changes and reduced the effectiveness of protective mechanisms. Alternatively, Nigerian children may have developed a mechanism to enable them to tolerate exposure to allergensfor example, as a result of exposure to frequent bacterial infections. ${ }^{17} 18$

Similar dissociation between atopy and asthma risk has also been reported in eastern and western Europe. ${ }^{19}$ Over a period of four years the authors showed a significant increase in the prevalence of hayfever and atopy in a cross section of school children without a resulting increase in the prevalence of asthma, asthma-related symptoms, or airway hyperresponsiveness. It was suggested that the exposure to a change in environmental factors-for example, western living conditions - may have occurred in later childhood and may have resulted in an increase in acquisition of atopy but with no effect on the prevalence of asthma symptoms. Similarly, it could be that the high prevalence of atopy and the low prevalence of asthma symptoms in Nigerian children may be due to exposure to factors occurring beyond infancy.

It is also possible that atopy to some allergens such as house dust mites may be more important than other allergens in predisposing children to having asthma. This hypothesis is supported by the finding that Australian children had a significantly higher prevalence of atopy to both house dust mites ( $D$ farinae and $D$ pteronyssinus) and rye grass. The relative potency of different allergens in increasing asthma symptoms, rather than causing sensitisation, is thought to be associated with the level of exposure, the size of the allergen bearing particles, and the enzymatic properties of the allergen. House dust mite allergens may be more potent than other allergens because they are more ubiquitous, because the airborne particles are small and are easily respired, or because of their enzymatic qualities. Several studies have shown that there is a strong relationship between exposure to house dust mite allergens and the prevalence and severity of asthma. ${ }^{20-22}$

In conclusion, we found that wheeze and persistent cough were less prevalent in Nigeria, caused less morbidity, and were less likely to be labelled or treated as asthma than in Australia. Also, in Nigeria asthma was more likely to be managed in the acute form. We found that the prevalence of atopy was similar in the two countries, although atopy to house dust mites and rye grass was more prevalent in Australia. Further studies are needed to determine why atopic children in Australia are more at risk of developing asthma. Such studies will have important implications for the primary prevention of asthma in countries where prevalence is high, and for preventing the acquisition of similar high rates in countries such as Nigeria where the prevalence of asthma is currently quite low.

1 The International Study of Asthma and Allergies in Childhood (ISAAC) Steering Committee. Worldwide variation in prevalence of symptoms of asthma, allergic rhinoconjunctivitis, and atopic eczema: ISAAC. Lancet 1998;351:1225-32.

2 Pio A. WHO programme on acute respiratory infections. Indian f Pediatr 1988;55:197-205.

3 Manfreda J, Becker AB, Wang P, et al. Trends in physiciandiagnosed asthma prevalence in Manitoba between 1980 and 1990. Chest 1993;103:151-7.

4 Salome CM, Peat JK, Britton WJ, et al. Bronchial hyperresponsiveness in two populations of Australian schoolchildren I. Relation to respiratory symptoms and diagnosed asthma. Clin Allergy 1987;17:271-81.

5 Peat JK, Gray S, Woolcock AJ. The epidemiology of asthma. Curr Opin Pulmon Med 1995;1:9-15.

6 Warrell DA, Fawcett IW, Harrison BD, et al. Bronchial asthma in the Nigerian savanna region. A clinical and laboratory study of 106 patients with a review of the literature on asthma in the tropics. Qf Med 1975;44:325-47.

7 Flynn MGL. Respiratory symptoms of rural Fijian and Indian children in Fiji. Thorax 1994;49:1201-4.

8 Peat JK, Britton WJ, Salome CM, et al. Bronchial hyperresponsiveness in two populations of Australian hyperresponsiveness in two populations of Australian
schoolchildren III. Effect of exposure to environmental allergens. Clin Allergy 1987;17:291-300.

9 Brand PL, Kerstjens AM, Jansen HM, et al. Interpretation of skin prick tests to house dust mite and relationship to other allergy parameters in patients with asthma and chronic obstructive pulmonary disease. F Allergy Clin Immunol 1993;91:560-70.

10 Peat JK, Toelle BG, Demand J, et al. Serum IgE levels, atopy and asthma in young adults: results from a longitudinal cohort study. Allergy 1996;51:804-10.

11 Somorin AO, Hunponu-Wusu OO, Mumcuoglu Y, et al. Mite allergy in Nigerians: studies on house dust mites in houses of allergic patients in Lagos. Ir F Med Sci 1978;147: $26-30$.

12 Aderele WI. Bronchial asthma in Nigerian children. Arch Dis Child 1979;54:448-53.

13 Yemaneberhan $\mathrm{H}$, Bekele Z, Venn A, et al. Prevalence of wheeze and asthma and relation to atopy in urban and rural Ethopia. Lancet 1997;350:85-90. 
14 Burney P. A diet rich in sodium may potentiate asthma: epidemiological evidence for a new hypothesis. Chest 1987; 91(Suppl): 143-8S

15 Burney PGJ, Neild JE, Twort CHC, et al. Effect of changing dietary sodium on the airway response to histamine. Thorax 1989;44:36-41.

16 Seaton A, Godden DJ, Brown K. Increase in asthma: a more toxic environment or a more susceptible population? Thorax 1994;49:171-4.

17 Holt PG. Immunoregulation of the allergic reaction in the respiratory tract. Eur Respir $\mathcal{F}$ 1996;22(Suppl):85-9s

18 Cookson WO, Moffat MF. Asthma: an epidemic in the absence of infection? Science 1997;275:41-2.

19 von Mutius E, Weiland SK, Fritzsch C, et al. Increasing prevalence of hay fever and atopy among children in Leipzig, East Germany. Lancet 1998;351:862-6.

20 Charpin D, Birnbaum J, Haddi E, et al. Altitude and allergy to house-dust mites. A paradigm of the influence of environmental exposure on allergic sensitisation. Am Rev Respir Dis 1991;143:983-6.

21 Sporik R, Holgate ST, Platts-Mills TAE, et al. Exposure to house-dust mite allergen (Der $p \mathrm{I})$ and the development of asthma in childhood. A prospective study. $N$ Engl $\mathcal{F} \mathrm{Med}$ 1990;323:502-7.

22 Platts-Mills TAE. Mechanisms of bronchial reactivity: the role of immunoglobulin E. Am Rev Respir Dis 1992;145: S44-7. 